\title{
Inbultwaerzeidnin.
}

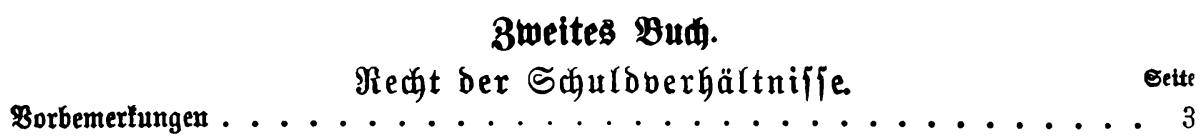

Erfter 2lbidhnitt.

Infalt der Sduldverbältuifle.

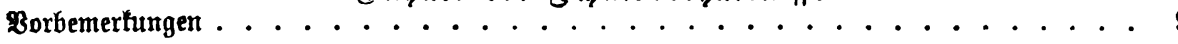

\author{
Exiter $\mathfrak{T} i$ tel.
}

Berpflidtung zur Reiftutg.

Borbemerfungen . . . . . . . . . . . . . . . . . . . 9

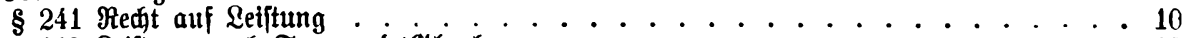

$\S 242$ Qeiftung nad Treu und Blauben . . . . . . . . . . . . . . . . . . . . 10

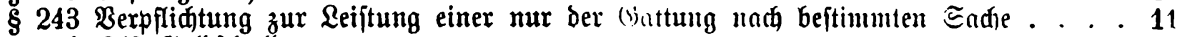

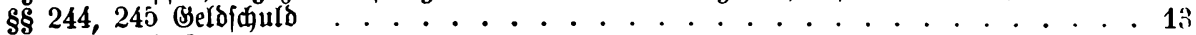

$\S \S 246-248$ Binjen . . . . . . . . . . . . . . . . . . . . . . . . 15

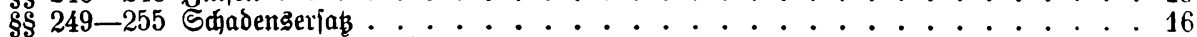

$\S \S 256,257$ Erją̧ von $\mathfrak{A} \mathfrak{n}$ fivendungen $\ldots \ldots \ldots$

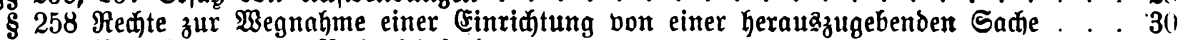

$\S 259$ Berpflidtung zur Rechenjđaftzlegung . . . . . . . . . . . . . . 31

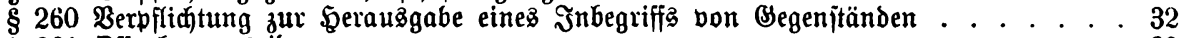

$\S 261$ Dffenbarungąeib . . . . . . . . . . . . . . . . . . . . . 33

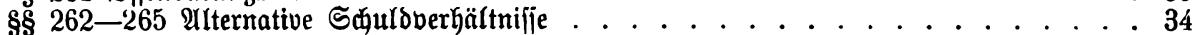

$\$ 266$ Theilleiftung . . . . . . . . . . . . . . . . . . 38

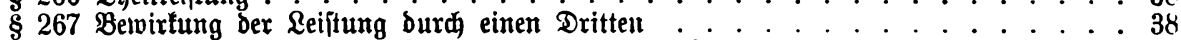

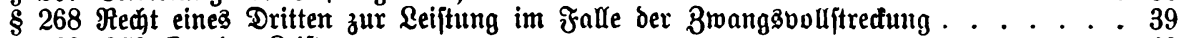

$\S \S 269,270$ Drt ber \&eiftung . . . . . . . . . . . . . . . . . . . . . . . 40

\$§ 271, 272 Beit der Leiftung. Bwijdenzinjen . . . . . . . . . . . . . . . . . 42

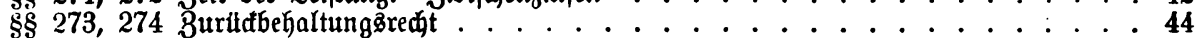

Borbemerfungen zu $\$ \S 275-290$. . . . . . . . . . . . . . . . . . . . . . . . . . . . . 47

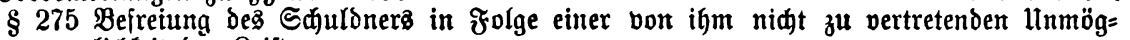
lidfeit ber Leiftung . . . . . . . . . . . . . . . 46

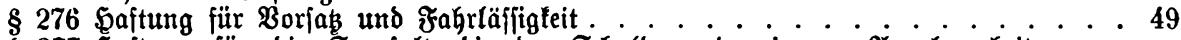

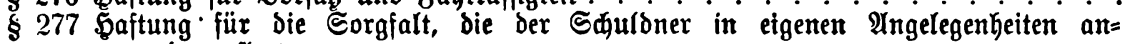

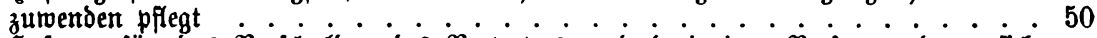

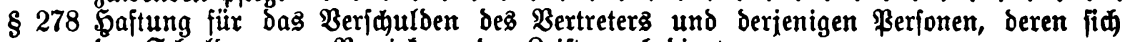
Der Sculdner zur Berwirfung ber Leiftung bedient. .......... 50

$\$ 279$ Saftung fïr ben Fall, baß ber Begenftand ber \&eiftung nur ber Bsattung nad be fimmt ift . . . . . . . 52

§ 280 Saftung des Săulonera, wenn bie Leiftung in Folge eines bon ihm zu bertreten= ben $\mathfrak{u m}$ itandes unntöglich ift . . . . . . . . . . . . . . . 52

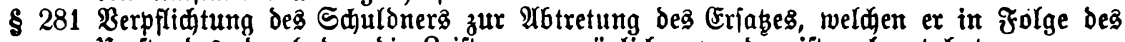
$\mathfrak{u}$ mitandes, burd ben bie leiftung ummöglid, geworden ijt, erlangt hat . . . 56

\$ 282 Belveialaft in Betreff des Berjuuldens . . . . . . . . . . . . 57

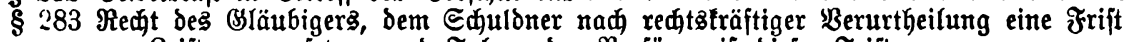

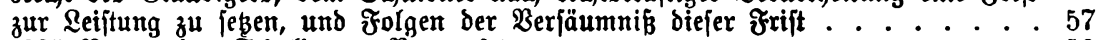

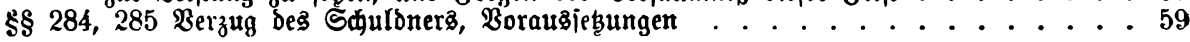




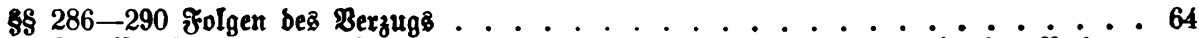

8291 Berpflidtung zur Berzinjung einer Beldjululd bon bem Beitpuntte ber Rectb=

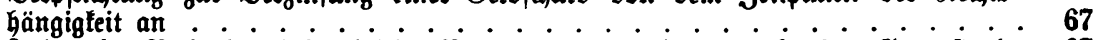

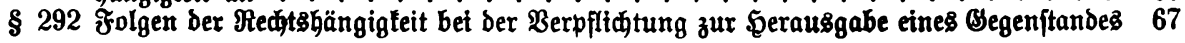

B weiter $\mathfrak{T} i$ tel.

Berzug beş Ğläubigers.

Borbemertungent . . . . . . . . . . . . . . . . . . . 68

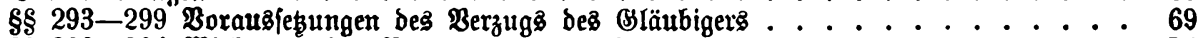

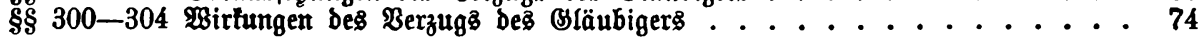

3weiter 21bihnitt.

\$dน

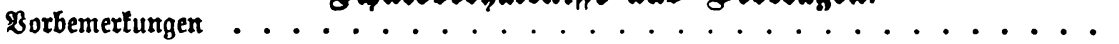

\section{Erfter $\mathfrak{T}$ itel.

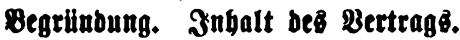

\$3orbemertungen 305 Exforderni geífäft. . . . . . . . . . . . . . . 78

$88306-308$ Bertrag auf eine unmöglide Leiftung . . . . . . . . . . 79

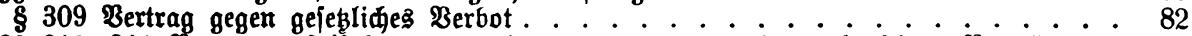

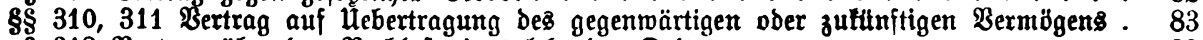

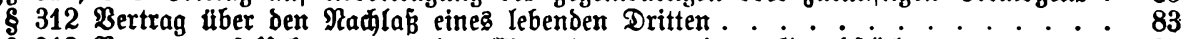

$\$ 313$ Bertrag auf $\mathfrak{M}$ ebertragung bez̧ (Etgenthum: an einem Brunditülfe . . . . . . 85

\$ 314 Eritredung Des Bertrags auf Ulebertragung ober Belaftung einer Sadje auf bas Bubehör . . . . . . . . . . . . . . . .

8§ 315, 316 Berträge, bei welđen die Leiftung oder deren $\mathfrak{u}$ mfang von einem der $\mathfrak{B e r}=$ tragidliésenden zu bejtimmen $i$ it............... 86

88 317-319 Berträge, bet weløen bie Leiftung von einem Ḋritten zu bejtimmen ijt.$\quad 88$

Borbemertungen ........ Gegenjettiger Bertrag. ........... 91

Breiter $\mathfrak{T}$ itel.

$\$ 320$ Berpflidtung zur \&eiftung 8 ug um 3 ug $\ldots \ldots \ldots$

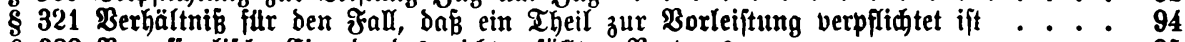

$\S 322$ \$rozefiualifde cinrebe bes nid)t erfülten Bertrags . . . . . . . 95

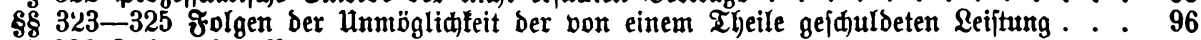

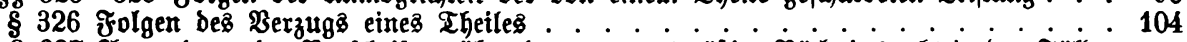

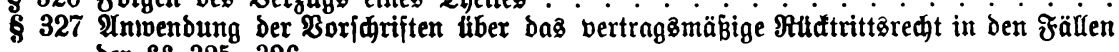

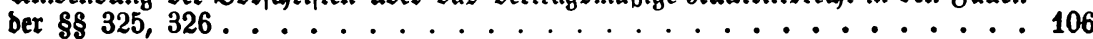

\section{Dritter $\mathfrak{T} i t e \mathfrak{l}$.}

Berfpreden ber Reiftung an einen Dritten.

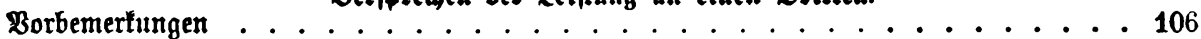

§ 328 Redt Dez Dritten auf bie veriprodiene Leiftung

$\$ 329$ Berpfliđtung eines Theiles zux Befriedigung des şläubigers bes anderen Theiles 109

8330 Berpflichtung zur Leiftung einer Lebenzberfiderung ober einer Leibrente an einen Dritten

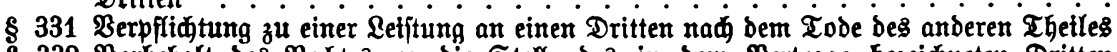

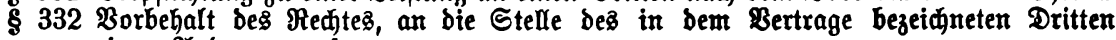
einen $2 \mathfrak{n}$ beren zu jesen

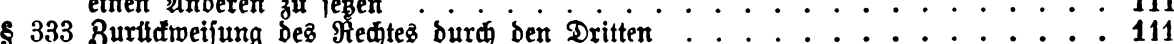

$\$ 334$ Einwendungen bes Berprentenden gegen den Dritten . . . . . . . 112

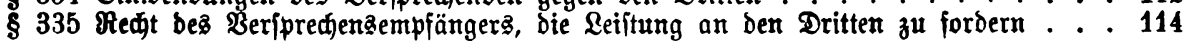

Bierter Titel.

Draufgabe. Bertraggftrafe.

Borbemertungen . . . . . . . . . . . . . . . . . . . 116

\$ళ 336-338 Draufgabe

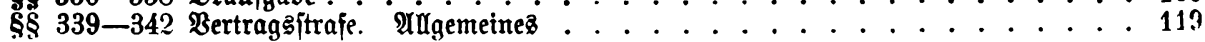




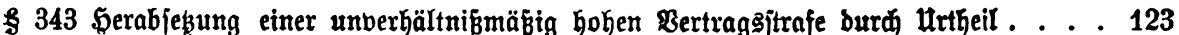

$\$ 344$ ünwirtfamteit ber zur Siđerung eines unwirfjamen Berjpredenz getroffenen Straf=

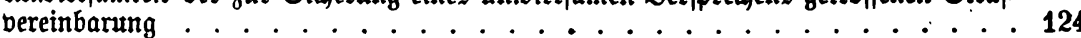

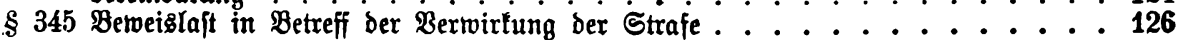

\section{$\mathfrak{F} \mathfrak{u} \mathfrak{n} \mathfrak{f t e r} \mathfrak{x} \mathfrak{i}$ el .}

Milidtritt.

Borbemertungen . . . . . . . . . . . . . . . . . . . 126

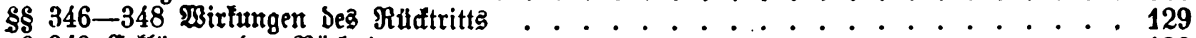

$\S 349$ Crflärung deả Rüđtrittå . . . . . . . . . . . . . . . . . . . . . . . . 129

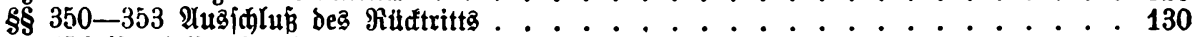

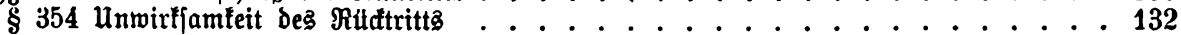

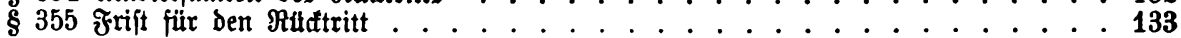

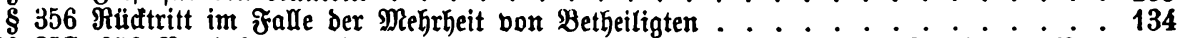

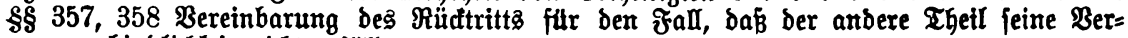

bindlidleit nidgt erfülft . . . . . . . . . . . . 134

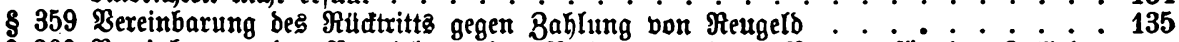

\& 360 Bereinbarung ber Berwirktıng Der Rechte aus einem Bertrag für ben

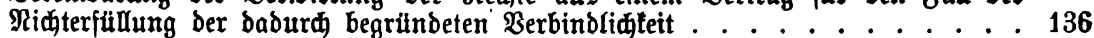

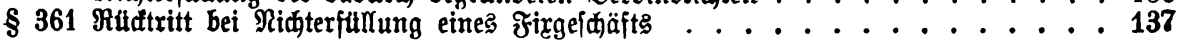

Dritter 2lbichnitt.

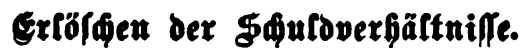

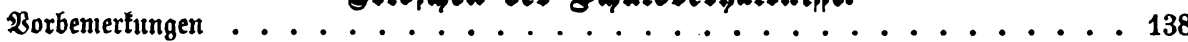

\section{Erfter Titel.}

Crfüulung.

Borbemertungen . . . . . . . . . . . . . . . . . 139

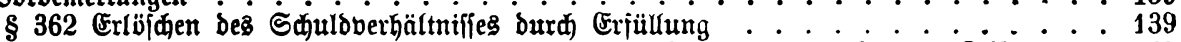

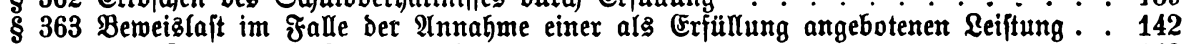

$\$ \S 364,365$ \&eiftung an Erfülungştatt . . . . . . . . . . 143

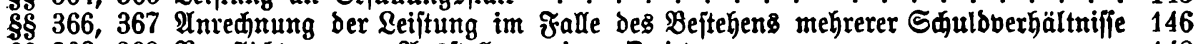

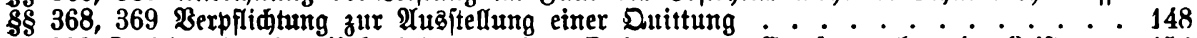

\$ 370 Legitimation des ueberbringers einer Duittung zur Empfangnahme ber Leiftung. 152

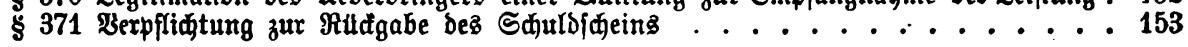

\section{Bueiter $\mathfrak{T}$ itel.}

\section{Sinterlegung.}

Borbemertungen . . . . . . . . . . . . . . . . . . 153

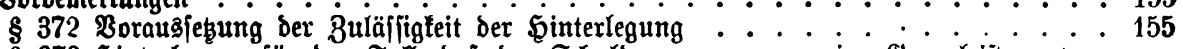

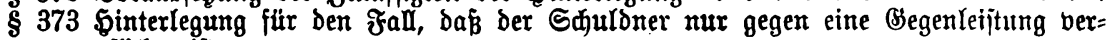
pflidetet ift

$\S 374$ Ort ber Sinterlegung . . . . . . . . . . . . . . . . . . . . . . 156

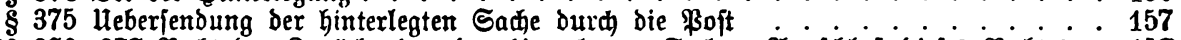

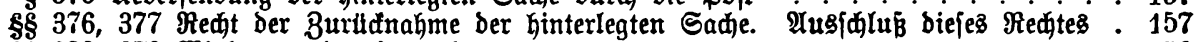

\$8 378, 379 WBirkungen ber Sinterlegung

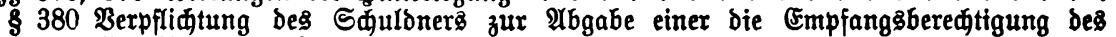
Bläubiger及 anerfennenden Erflärung ............... 161

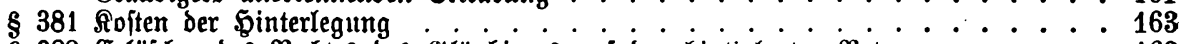

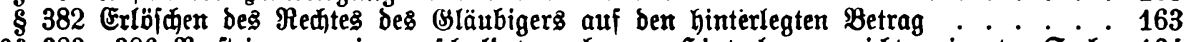

ş 383-386 Beriteigerung einer gefđuldeten, aber zur Sinterlegung niळt geeigneten Sade 164

\section{Dritter Titel.}

Aufredunng.

Borbemertungen . . . . . . . . . . . . . . . . . . . 168

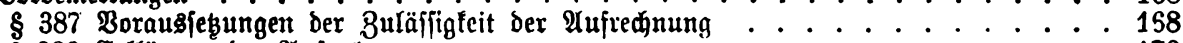

$\$ 388$ Ertlärung ber $\mathfrak{A}$ ufređ̆nung . . . . . . . . . . . . . . . . . . 170

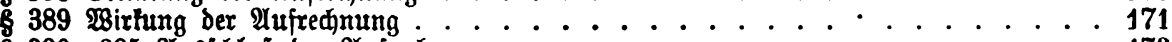

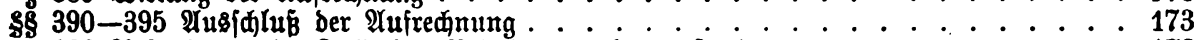

$\$ 396$ भufrednung im falle dę Beftehent mehrerer f̧orberungen . . . . . . 178 


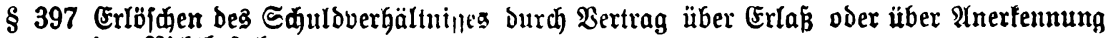

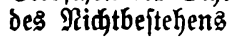

\section{Dierter 21bidhnitt. \\ debertragung Der Forderung.}

Borbemertungen .......................... 182

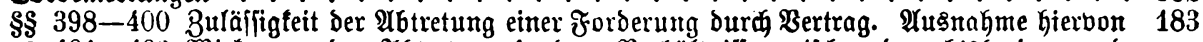

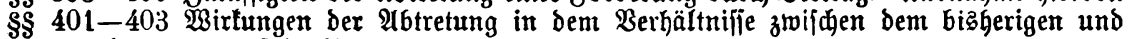

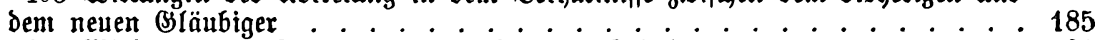

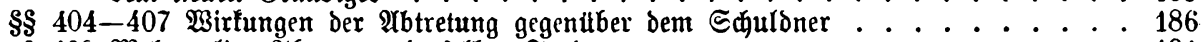

\$ 408 Mehrmalige QAbtretung Derfelben ₹orderung . . . . . . . . . . . . . . . . 191

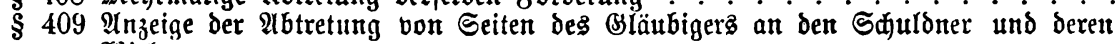
wirfungen

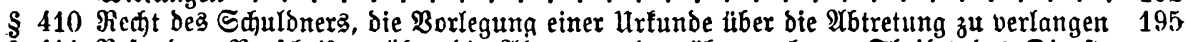

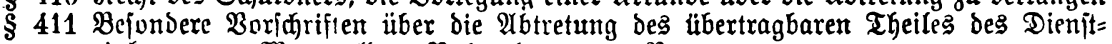

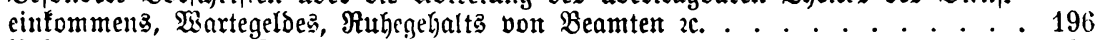

§ $412 \mathfrak{U}$ ebertragung einer Jorderung traft (Sejebes . . . . . . . . . . . . . . . 197

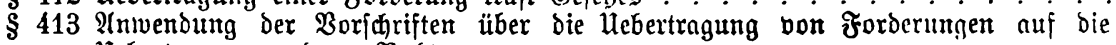
Ulcbertragung anderer Rechte................. 197

fünfter 2 bbjanitt.

Săuroübernafjme.

Borbemerfunqen ........................ . . 199

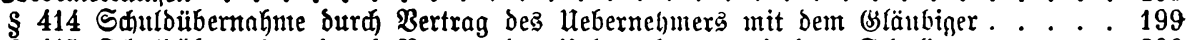

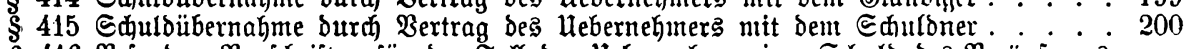

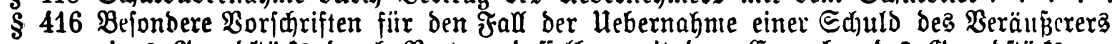

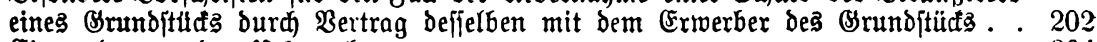

$\S 417$ Einwendungen bes Uebernehmerz . . . . . . . . . . . . . . . 204

$\S 418$ Wirkungen der Єaulbïbernahme . . . . . . . . . . . . . . . . . . . . . . 205

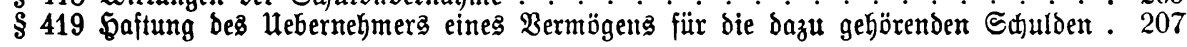

\section{Sechiter Ubjhnitt.}

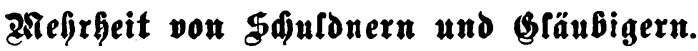

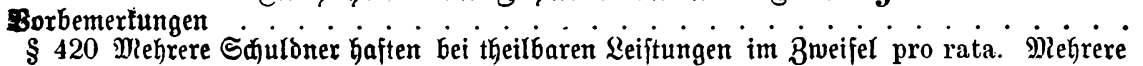

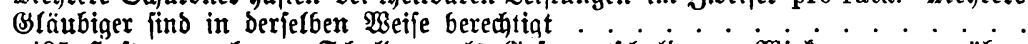

§§ 421-425 Waftung mehrerer Sduldner als \$sfammtjduldoner. Wirfungen gegenüber Dem Bläubiger . . . . . . . . . . . . . . . . . . . 211

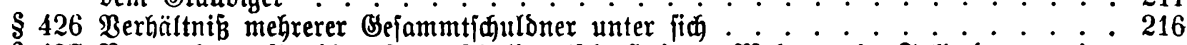

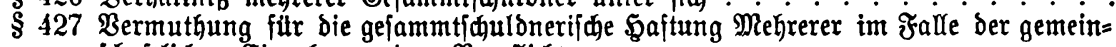
idaftlthen Eingebung einer Berpflithtung

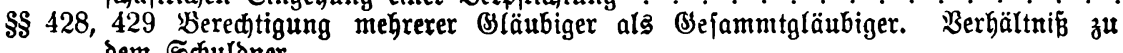
dem Єnuldner . . . . . . . . . . . . . . 219

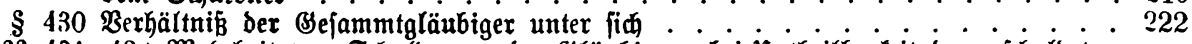

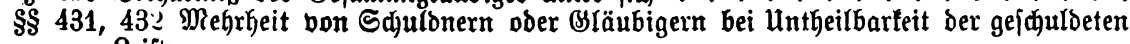

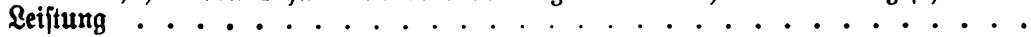

Siebenter Jbjąuitt.

Einzelte \$d đulovergältuiffe.

Borbemerlungen ................
Eriter Tttel.

Rauf. Taนid.

Borbemerfungen ...................... 
I. Arugereine Boxidriftert. Seite

Borbemerlungen . . . . . . . . . . . . . . . . . . 225

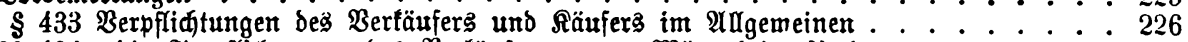

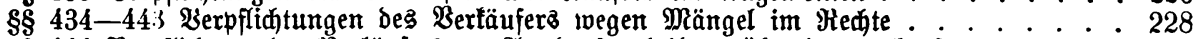

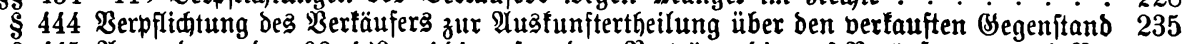

$\S 445$ Anwendụng der $\$ \S 433-444$ auf andere Berträge, die auf Beräußerung und $\mathfrak{B} e=$ lajtung geridtet jind .................... 236

$\S \S 446,447 \mathfrak{U}$ ebergang ber Đeefahi . . . . . . . . . . . . . . . . . . . . . . 236

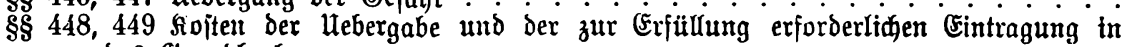
Dag Brambbud

\$. 450 Berwendungen deả Berfäufers

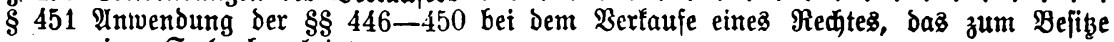
einer Sade beredtigt . . . . . . . . . . . . . . . . . 241

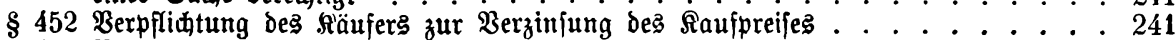

$\S 453$ Beftimmung de马 Marłtpreijes als Siafpreis . . . . . . . . . . . . 242

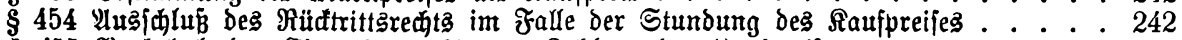

$\S 455$ Sorbehalt bes Eigenthums bis zur Zahlung bes Siaufpreifes. . . . . . . . 243

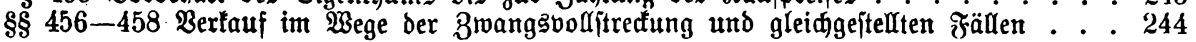

\section{Gewährleiłtung wegen Mängel Dex Sađe.}

Borbemerfungen . . . . . . . . . . . . . . . . . . . . . . . . . 246

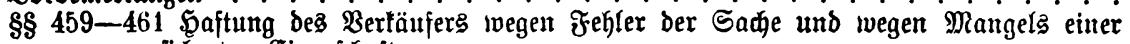

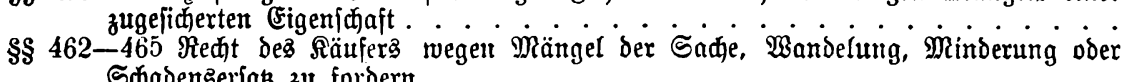

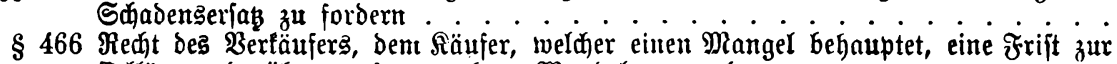

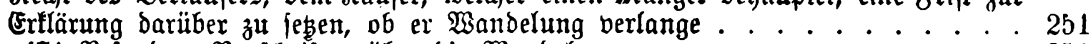

$\S \S 467-471$ Bejondere Borjđriften

$\$ \$$ 472-475 Befondere Borjd)riften über die Minderutg . . . . . . . . . . . . 255

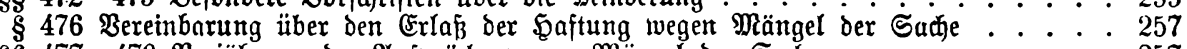

$\$ 8$ 477-479 Berjährung dex 2lniprühe wegen Miängel dex Sade . . . . . . . . . . . 257

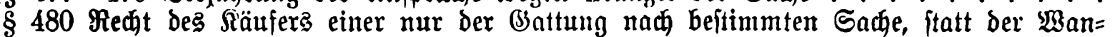
belung $2 c$. Die Rieferung einer mangelfreien Sadie zu fordern . . . . . . 260

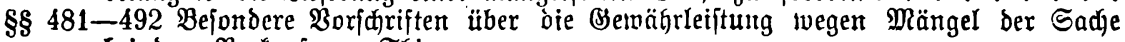
bei dent Berfauf nout Thieren . . . . . . . . . . . . . . . . . 261

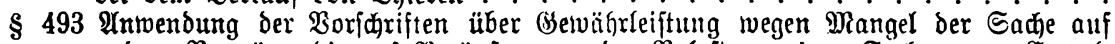
andere Berträge, bie auf Beräußerung ober Belajtung einer હađje gegent Entgelt gerid)tet find

西

\section{Bejoudcre Arten des Raufes.}

Borbemerfungen

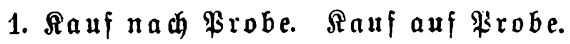

Borbemerlungen . . . . . . . . . . . . . . . . . . . . . . 269

\& 494 Berfauf nach $\mathfrak{B r o b e}$. . . . . . . . . . . . . . . . . . . . . . . . 269

$\$ \S 495,496$ Berlauf alıf $\mathfrak{B}$ robe . . . . . . . . . . . . . . . . 269

\section{Wiedertauf.}

Borbemertungen . . . . . . . . . . . . . . . . . . 271

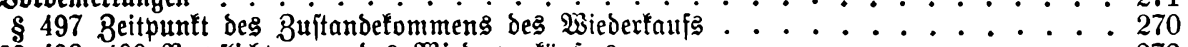

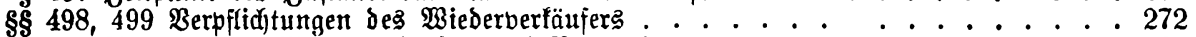

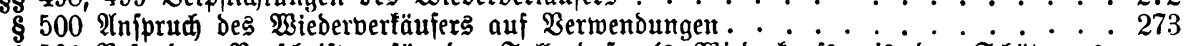

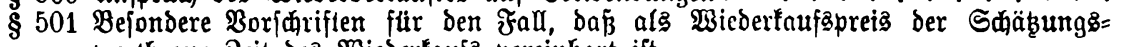
werth zur Beit deş $\mathfrak{B}$ iederfaufz vereinbart ift ............ 274

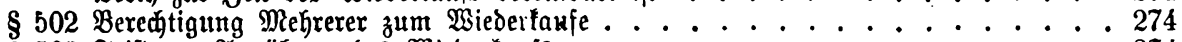

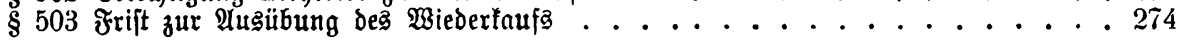

3. Sortauf.

Borbemerfungen . . . . . . . . . . . . . . . . . . 275

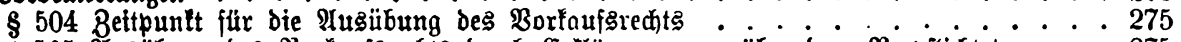

§ 505 भ̂a 


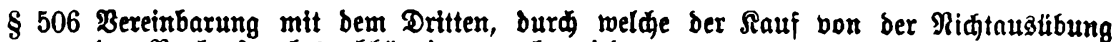

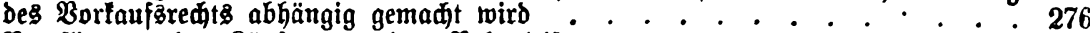

$\$ 507$ Berpflidtung bes §äufersิ zu einer Rebenleiftung . . . . . . . . . . . 277

$\$ 508$ Sertauf mehrerer Begenftände zu einem Bejamnttpreife . . . . . . . . . 277

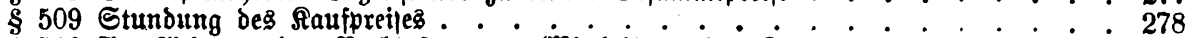

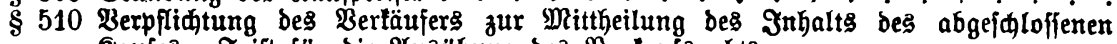

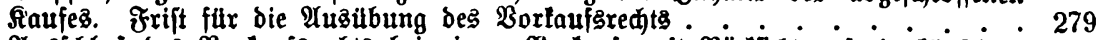

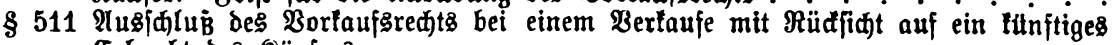
Exbredht dez Siäufers

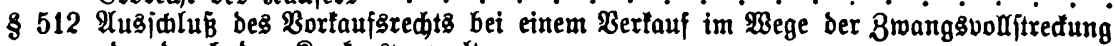
pder Jurळ den Ronfuraberwalter . . . . . . . . . . . . . . . . . 280

$\$ 513$ Borfaufäberedtigung $\mathfrak{D}$ ehrerer

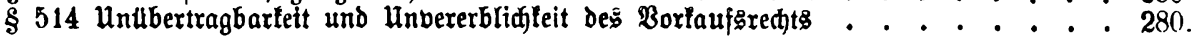

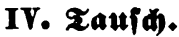

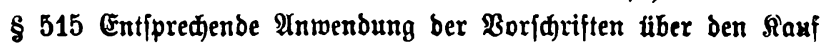

\section{Bweiter Titel. \\ Sdenlung.}

Borbemertungen

$\S \S 516,517$ Begriff Der Śthentung

$\cdot \cdot \cdot \cdot \cdot \cdot \cdot \cdot \cdot \cdot \cdot \cdot \cdot \cdot 20^{\circ}$

$\$ 518$ form bes Shenfungsberfpredens . . . . . . . . . . . . . . . . 284

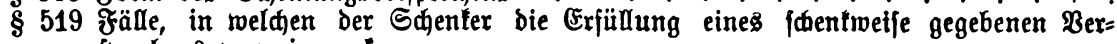
fpredens verweigern fann . . . . . . . . . . . . . . . . 285

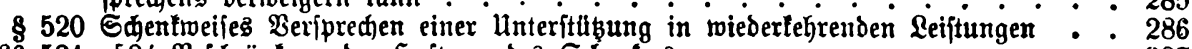

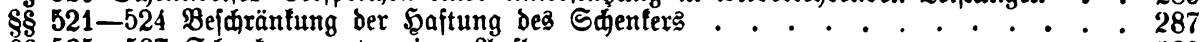

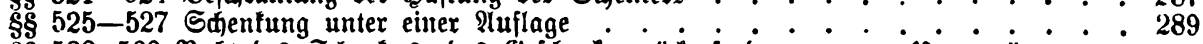

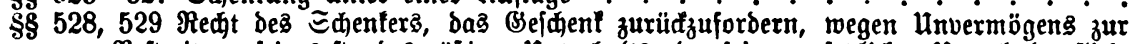

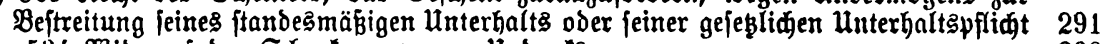

$\$ \S 530-534$ Wiberruf ber Shenfung wegen Undanła ........... 293

\section{Dritter Titel. \\ Miethe. Sadt.}

\section{Mnietbe.}

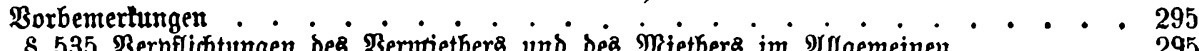

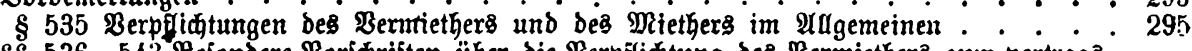

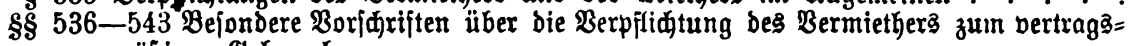
mäßigen Bebraudie

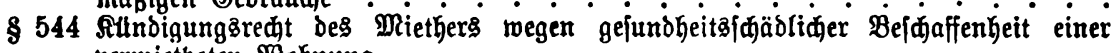
vermietheten $\mathfrak{B o g}$ ?ung . . . . . . . . . . . . . . . . 302

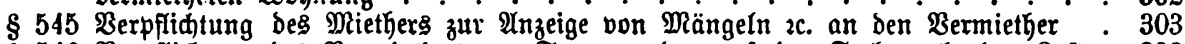

\$ 546 Berpflidtung bes Bermiethers zur Tragung ber auf ber Eađe ruhenden \&aften 303

$\S 547$ Berpflidtung Des Bermietherg zum Erjake von Berwendungen an Den Miether.

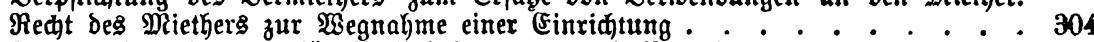

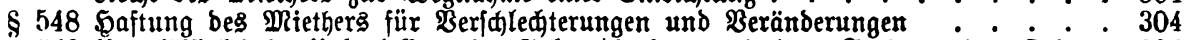

\$ 549 uñ

$\S 550$ Bertragivibriger Bebrauh ber gentietheten Sade . . . . . . . . . 305

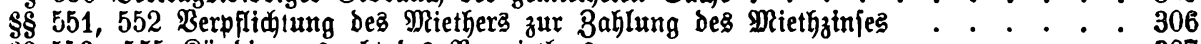

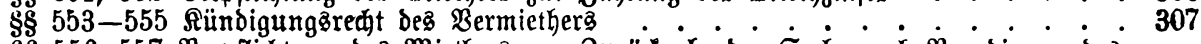

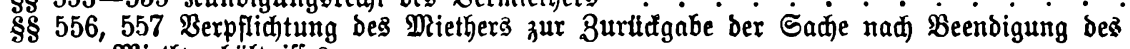
MRiethyerhältniffea .

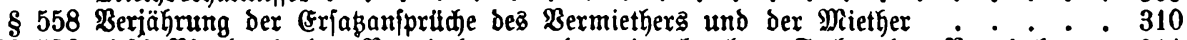

§§ $559-563$ Pfandredt des Bermiethers an Den eingebradten Sadhen des

$\S 564$ Beendigung des Mieţ́berfältniffes . . . . . . . . . . . . . . 314

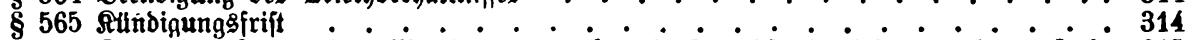

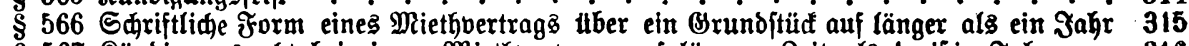

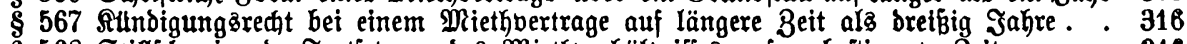

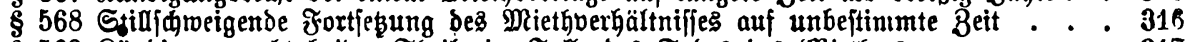

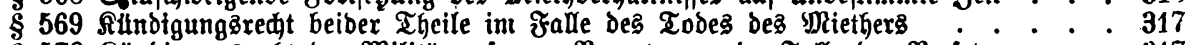

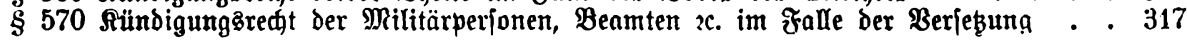




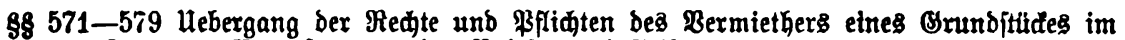
Jalle ber Beräuberung ober Belaftung beffelben auf bem (Frwerber (siauf bricht nidft Miethe)

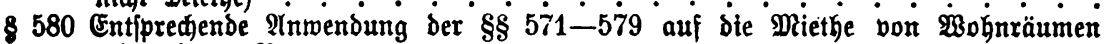

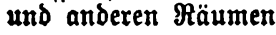

Eetie

\section{Pad)t.}

Borbemertungen

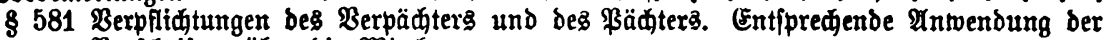
Borjariften über die Miethe

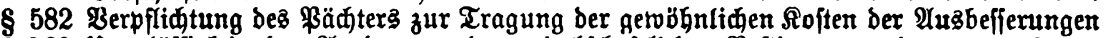

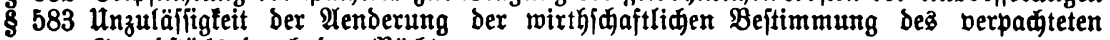
Brandjtüđđa burd ben ßädter

§ 584 Beitpuntt Der Entriđatung bes ßachtzinjes . . . . . . . . . . . . . .

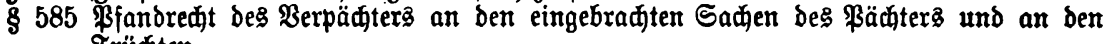

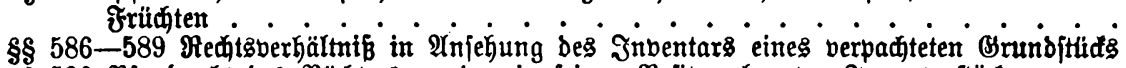

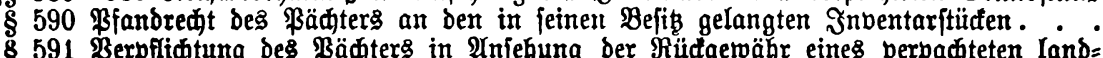

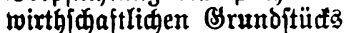

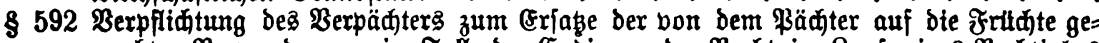
madten Berwendungen im Falle ber Endigung Der ßadt im Laufe eines \$ađtjahrs

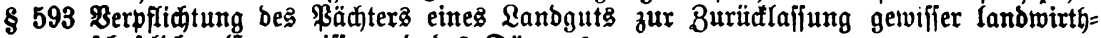
fíaftlider Erzeugniffe und des Dungers

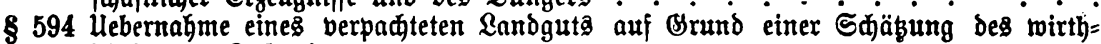
idaftliden 8 uftandez .

§ 595 ßaht auf unbétimmte Beit . . . . . . . . . . . . . . . . 333

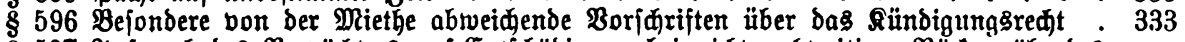

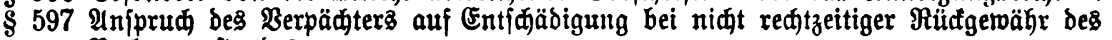
ßađtgegenftandes

\section{Bierter Titel.}

\section{Reihe.}

Borbemertungen . . . . . . . . . . . . . . . . . . . . . . 335

\$8 598-600 Berpfliqtungen bez $\mathfrak{B}$ erleikerz. . . . . . . . . . . . . . . . . 336

$\$ \$ 601-604$ Berpflidtungen bes Entleigers . . . . . . . . . . . . . . . . . 337

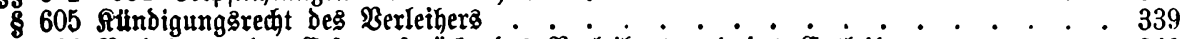

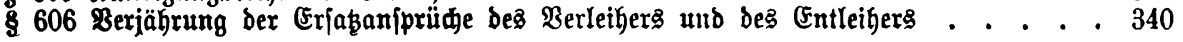

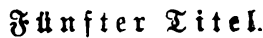

\section{Darlchen.}

Borbemerhungen . . . . . . . . . . . . . . . . . . . . 340

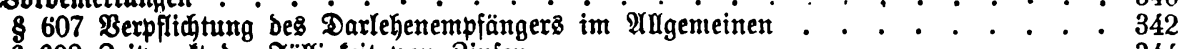

$\$ 608$ Beitpunft-Der \&äligfeit von Binjen . . . . . . . . . . . . . . 344

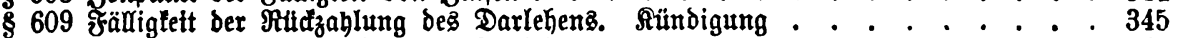

$\$ 610$ Berlpreden der Singabe einea Darlehens . . . . . . . . . . . . . 346

\section{Sedifter Titel.}

\section{Dienitbertrag.}

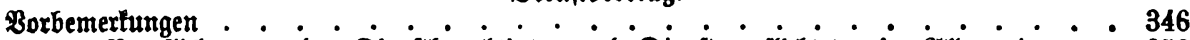

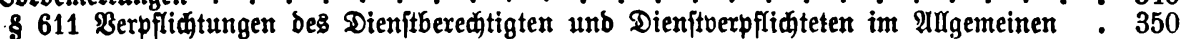

$\$ 612$ Stinjałweigende Bereinbarung ber Berguttung . . . . . . . . . . . . 35̄2

8613 Berpflidutung zux Reiftung der Dienfte in ßerion . . . . . . . . . . . . . 352

814 Bettpuntt, in weldem bie Yergütung zu leiften ift . . . . . . . . . . . 353

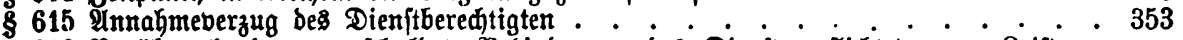

\$ 616 Borubbergehende unveriduldete Behinderung des Dienjtberpflidteten zur Leifiung Der Dienite

8617 Befonbere Berpfliciturngen bes Dienttberedtigten bei einem bauternden Dienitber

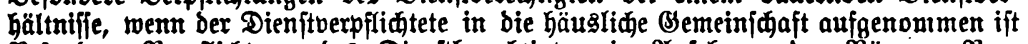

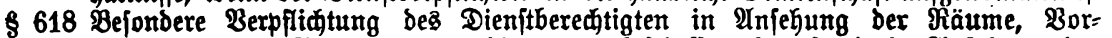

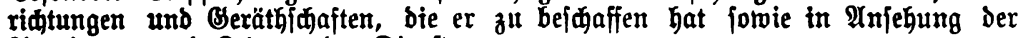
Ânoronung und Leitung ber Dienjte 


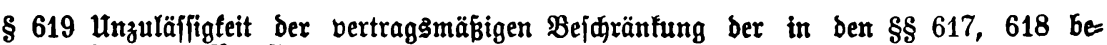
ftimmten Berpflidutungen . . . . . . . . . . . . . . . . . . . 360

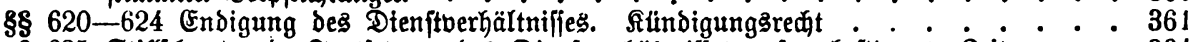

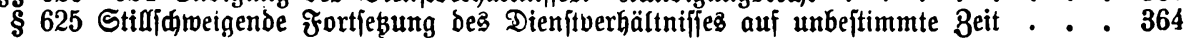

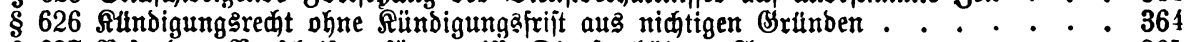

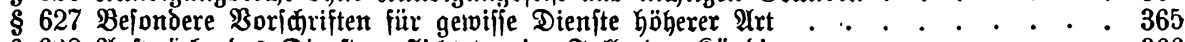

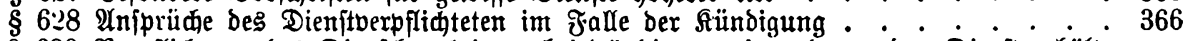

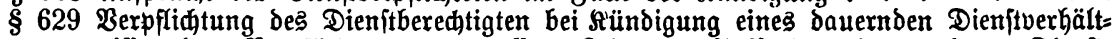
niffeß Dem Berpflidteten angemeffene Beit zum Uuffudjen eines anderen Dienjt=

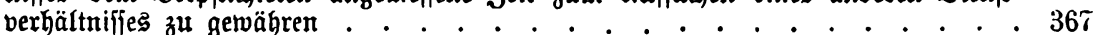

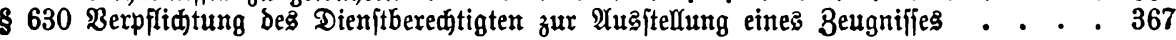

\section{Siebenter Titel.}

\section{Werfuertrag.}

Borbemerfungen . . . . . . . . . . . . . . . . . . . . . . . . 368

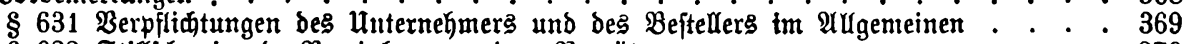

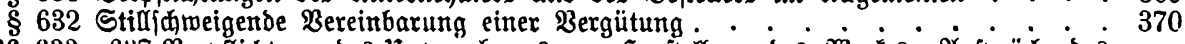

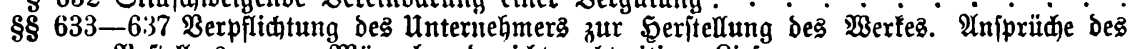

Beftellers wegen Mängel und niabt rechtzeitiger Rieferung ....... . . 371

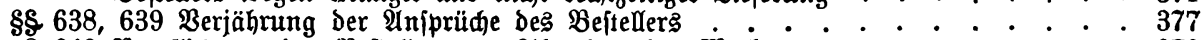

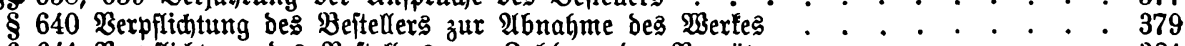

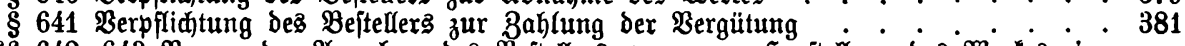

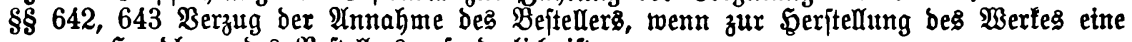
\$andlung bez Beftellers exforderlich ift. . . . . . . . . . . . . . 382

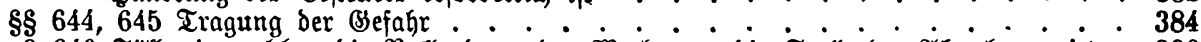

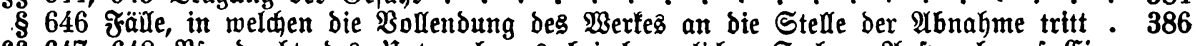

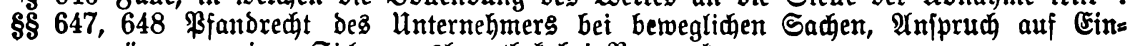
räımung einer Sidjerungahypothef bei Bauwerten . . . . . . . . . . 386

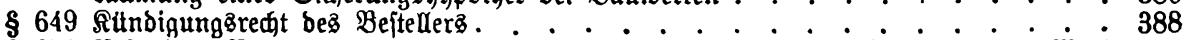

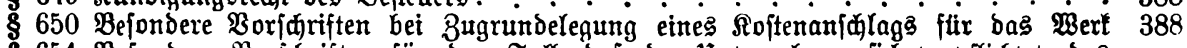

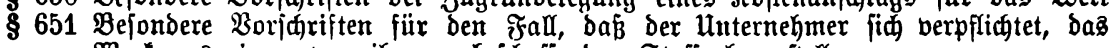
Berł aus einem von ifm zu befaffenden Stoffe herzuftellen . . . . . 389

\section{$\mathfrak{A}$ dter Titel. \\ Mällervertrag.}

Borbemertungen . • • • . • .

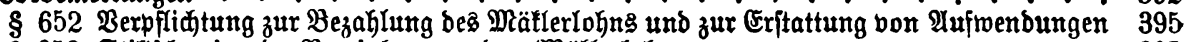

§ 653 Stinjđweigende Bereinbarung des Mäklerlohns . . . . . . . . . 397

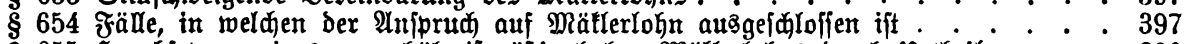

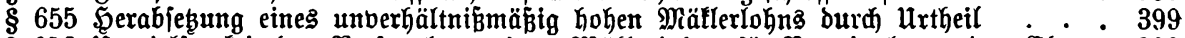

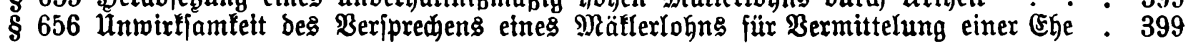

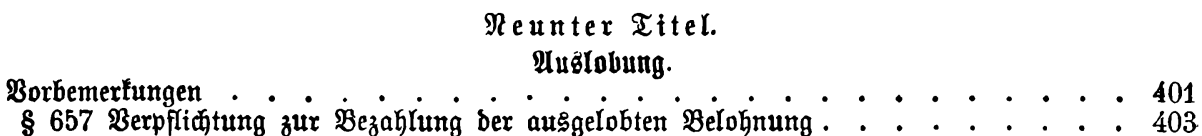

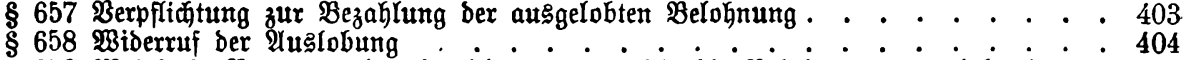

$\$ 659$ Mehrfache Bornahme ber ફandlung, für welde bie Belohnung auggelobt ift. 404

$\$ 660$ Mitwirkung Mehrerer zu bem Erfolge, für welchen bie Belohnung ausgelobt ijt. 405

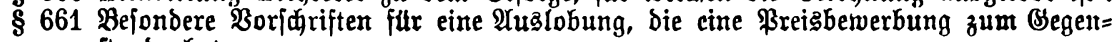
ftande hat ....................... 407

\section{Behnter Titel. Aluftrgg.}

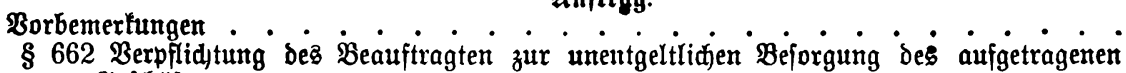
(S)eidäáts

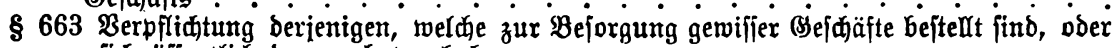

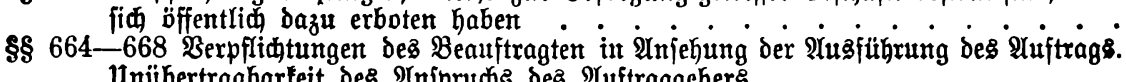




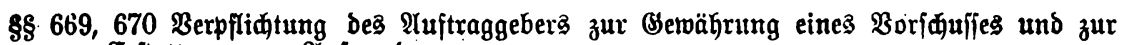

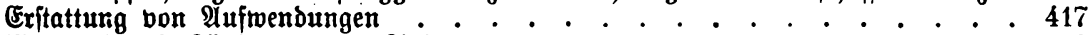

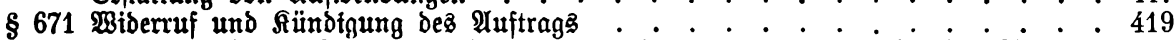

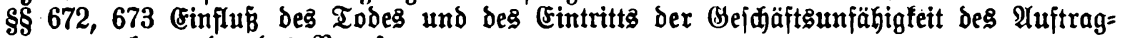

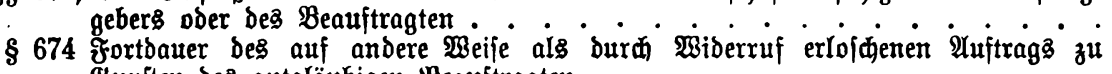

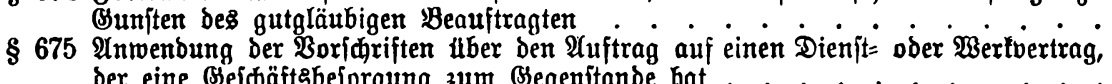
Der eine Bejđäftgbeforgung zum Begenjtande hat.. . . . . . . . . . . 422

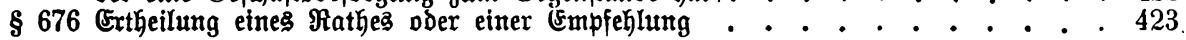

\section{Elfter Titel.}

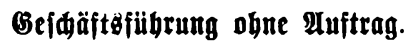

Borbemertungen . . . . . . . . . . . . . . . . . . . . . . 425

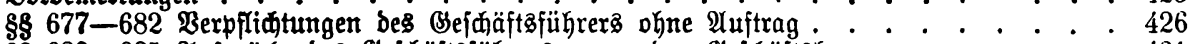

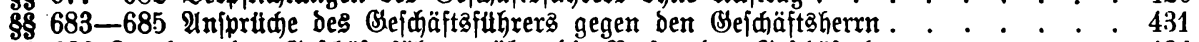

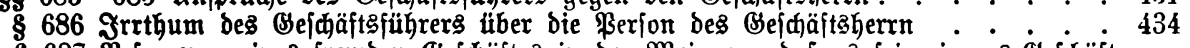

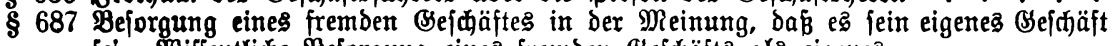

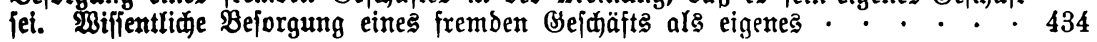

Bivölfter Titel.

Bermabrung.

Borbemerfungen . . . . • . • . •

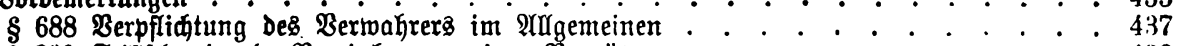

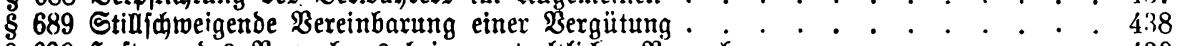

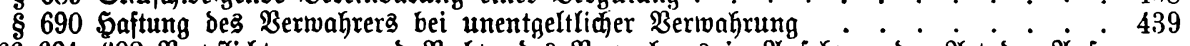

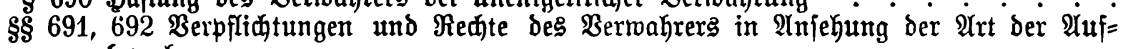
bewahrung . . . . . . • . . . . . . . . . . 439

§ 693 भ̂̉n

§ 694 \$aftung bes Sinterlegers für ben Durd bie Beidaffenheit ber hinterlegten Sadje Dem Berwahrer entitandenen Sdjaden . . . . . 441

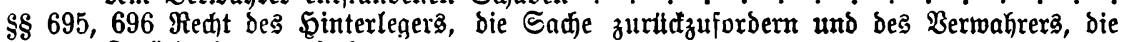
Burüdnafme zu fordern . . . . . . . . . . . . . . . . . . 441

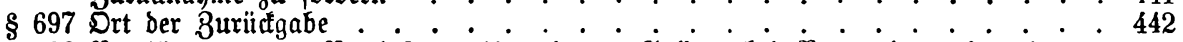

\$ 698 Berpflidtung zur Berzinjung hinterlegten Bjeldes bei $\mathfrak{B}$ erwendung im eigenen

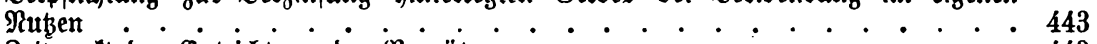

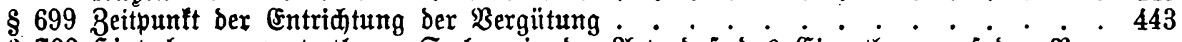

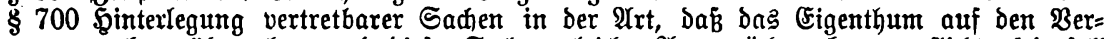
wahrex übergehen, und biefer Sadjen gleider $\mathfrak{A}$ rt zuriidzugeben verpflidet fein fol

\section{Dreizehnter Titel.}

\section{Cinbringung bon Sadjen bei Gajtwirthen.}

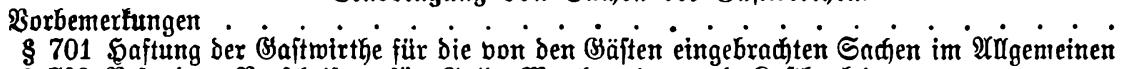

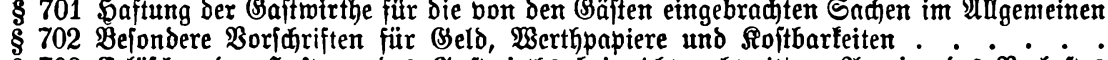

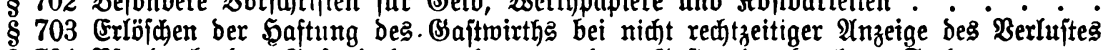

$\$ 704$ \$fandredt des Saftwirths an ben von bem (Sajte eingebradjten Eadjen . . 450

Borbemerfungen . . . . . . . . . . . . . . . . . . . . . . . 451

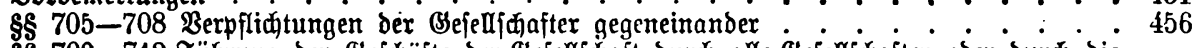

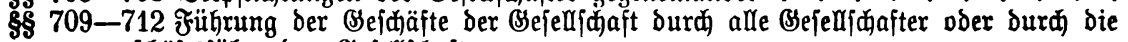

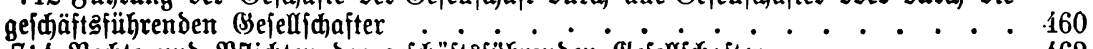

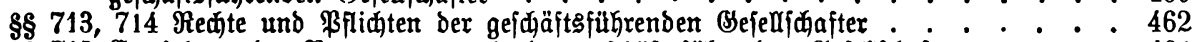

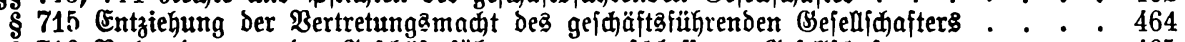

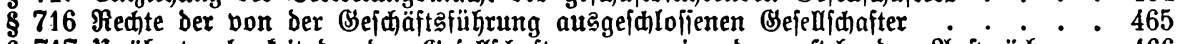

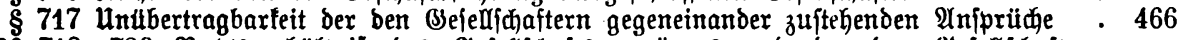

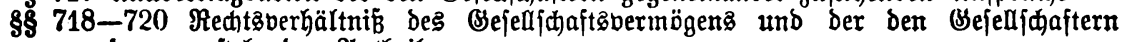
baran zujtehenden Antheile ...

\$§ 721, 722 Intheil ber Befellfafter an Beminn umb Berlujt . . . . . . . . . . 470 


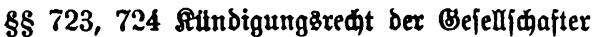

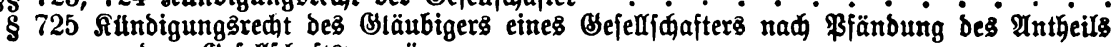
an bem Bsefellidjaftşbermögen

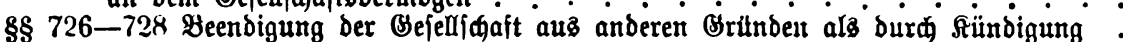

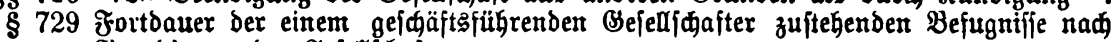
Beendigung ber Befellidaft

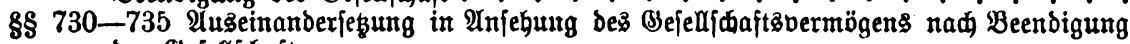
Der Bsejellidaft

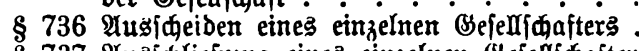

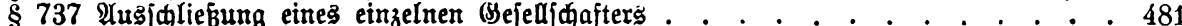

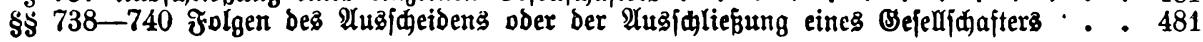

Oتemeinjidaft.

\section{Funfzebnter Titel.}

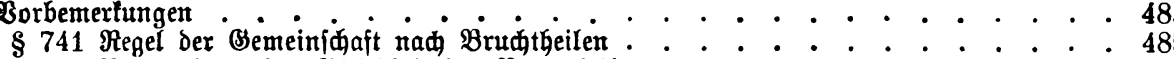

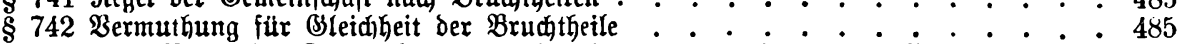

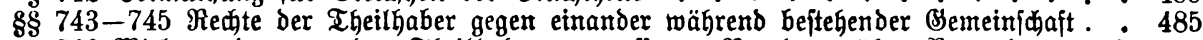

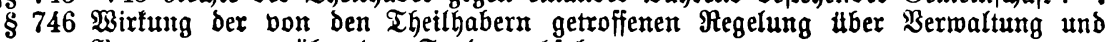
Benuzung gegeniiber den Sondernadfolgern .

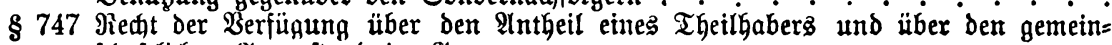
idaftlidien Begenitand im Banzen

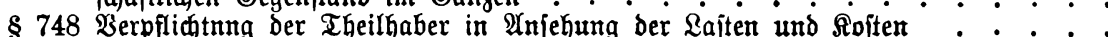

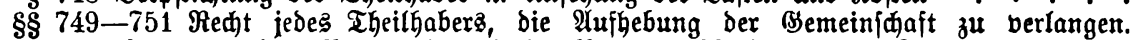

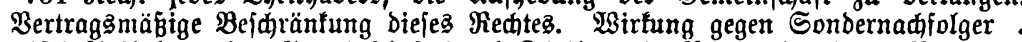

\$§ 752-754 Aufhebung Der Bemeinidaft Durd Theilung in Ratur ober burd Bertauf :

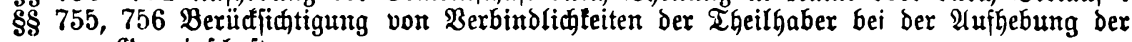
Bemeinjuaft

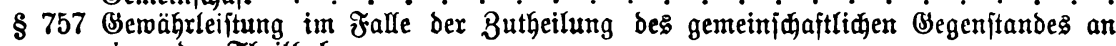
einen ber Theilhaber

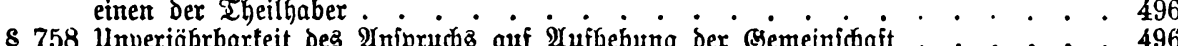

\section{Sed̆zehnter Titel.}

Seibrente.

Borbemertungen . . . . . . . . . . . . . . . . . . . . . . . . : 497

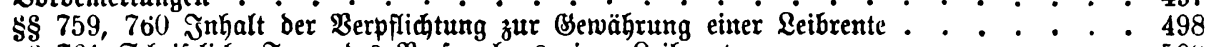

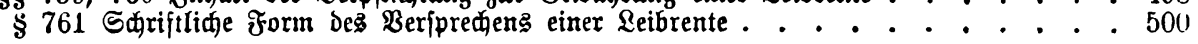

\section{Siebzegnter Titel.}

Spiel. $\mathfrak{2} 8 \mathrm{ctte}$.

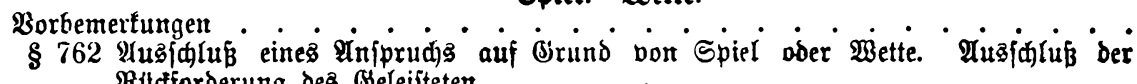

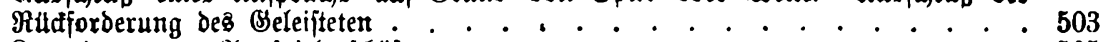

§ 763 Rotteriebertrag. Ausfpielgefä̈ft . . . . . . . . . . . . . . . . 505

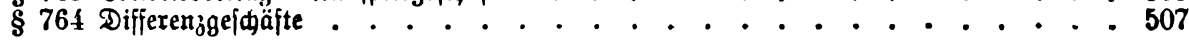

\section{Adtzehnter Titel.}

\section{Buirgidaaft.}

Borbemerfungen . . . . . . . . . . . . . . . . . . . . . . . . 508

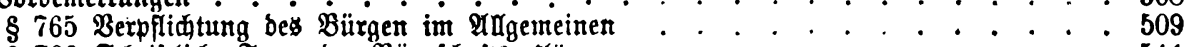

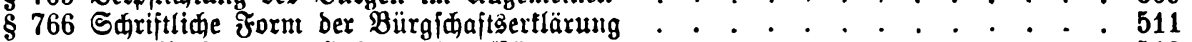

$\$ \S 767,768$ umfang Der \$aftung Dę Bürgen . . . . . . . . . . . . . . . . . . 512

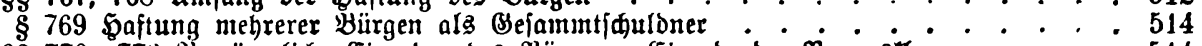

$\S \S 770-773$ Serzöperliche Einreden des Bürgen. Eimrede ber Boraustlage . . . . . 514

\$ 774 grolgen ber $\mathfrak{B}$ efriedigung bes Bläubigers durd ben Bürgen . . . . . . . . . 517

775 3erbürgung im $\mathfrak{A}$ uftrage des \$auptifuldners

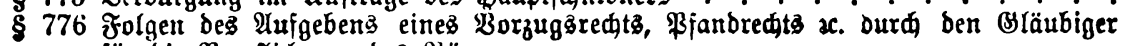

für bie Berpflidutung des \$ürgen . . . . . . . . . . . . . . . . 519

$\S 777$ Berbürgung auf bejtimmte Beit . . . . . . . . . . . . . . . . . . 520

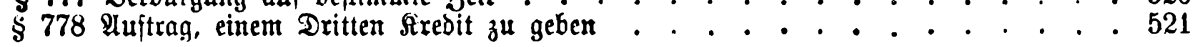




\section{Reunzegnter TiteL.}

Bergleid.

Geite

Borbemerfungen . . . . . . . . . . . . . . . . . . . 522

8779 Begriff und Wirkungen des Bergleids . . . . . . . . . . . . . . . 525

3 to a $\mathfrak{z}$ ig it ex $\mathfrak{T} i$ tel.

Sdulbveripreden. Sdjulbanerfenntnik.

Borbemertungen . . .

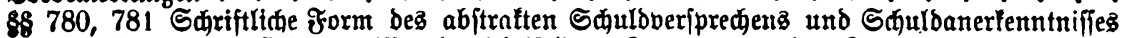

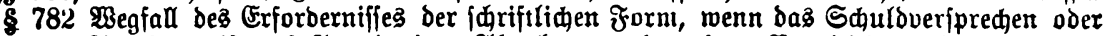

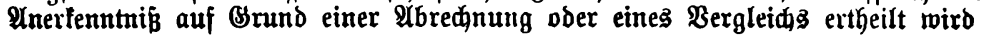

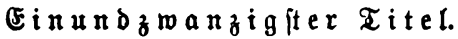

Unweijung.

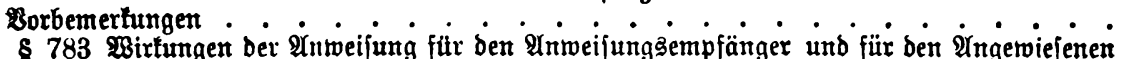
88784 , 785 Berpflidtung des 9ingewiejenen in Folge ber Alnnahne der Ânweijung.

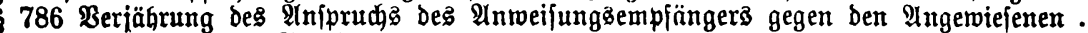
$887 \mathfrak{A}$ nweifung auf. Shuld

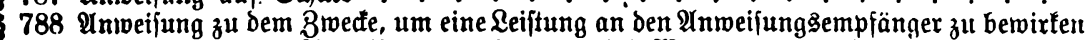

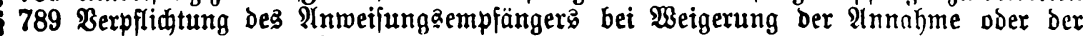
Leiftung burd den Angewiejenen.

790 Biberruf ber 2 tniveijung . . . . . . . . . . . . . . . . . 542

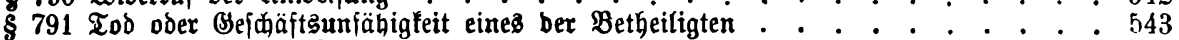

792 Ulebertragung der $\mathfrak{A}$ nweijung . . . . . . . . . . . . . . . . 543

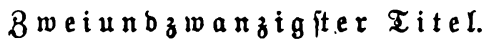

\section{Shuloveridreibung auf bea 3 maber.}

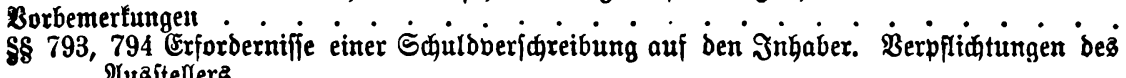
Aubitellers . . . . . . . . . . . . . . . . . . . 547

8795 Erforberniß ber itaatliden Benehnigung bei Sduldberidreibungen auf Beld : . 552

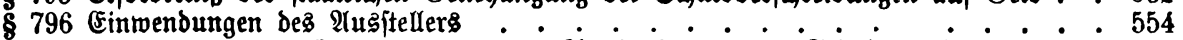

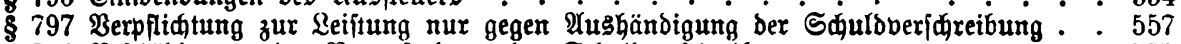

8798 Bejđäbigung oder Berunjtaltung ber Sđuldveriđreibung . . . . . . 557

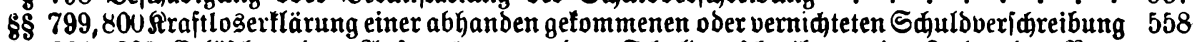

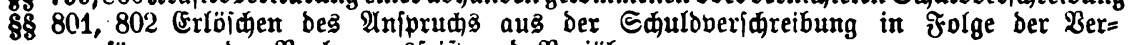
jäumung ber Borlegung gfrift und Berjährung . . . . . . . . . . 559

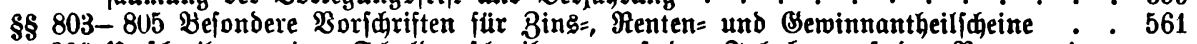

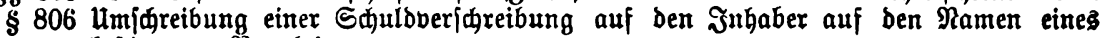

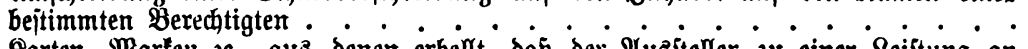

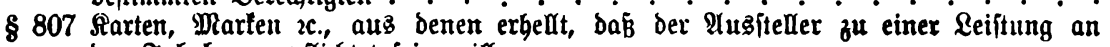
Den Jñ

8808 Legitimationspapiere.

Dreiundzonazigiter $\mathfrak{D} i t e \mathfrak{l}$.

\section{Worlegung von SadeH.}

Borbemerfungen

.

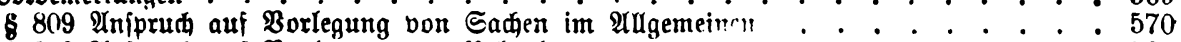

810 Anjprud auf Borlegung von urfunien ................. . . . 571

$\S 811$ Drt ber Worlegung . . . . . . . . . . . . . . . . . . . . . . 573

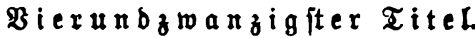

\section{Uugeredtfertigte Bereiđerung.}

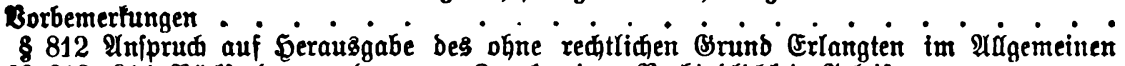

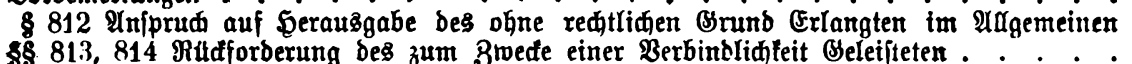

815 Rutuforberung wegen Riäteintritts bes mit einer Leiftung bezmeften Crfolges.

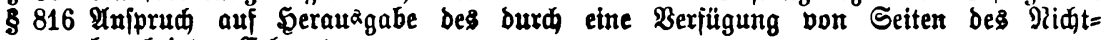
beredtigten Erlangten 


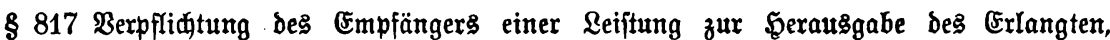
wenn er burd bie Annahme gegen ein Bejes oder gegen bie guten Sitten ber= ftoken hat

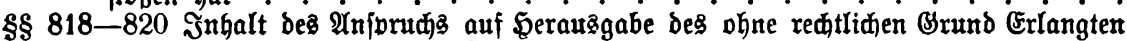

§ 821 Recht zur Berweigerung ber Erfüllung einer ohne rectitliden Brund eingegangenen Berbindlichteit, wenn ber $\mathfrak{A}$ njprud auf Befreiung berjährt ijt.

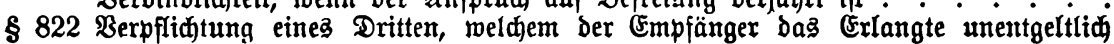
zugemendet hat

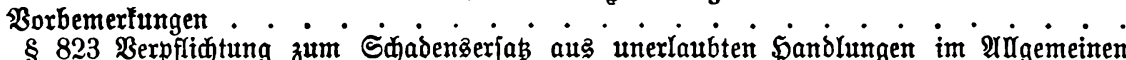

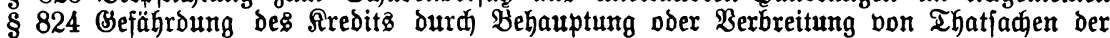
Wahrheit zumider .

§ 825 Beftimnung einer Frauenßperfon burd Sinterlift 2 . zur Bejtattung ber auser= eheliden Beimofnung

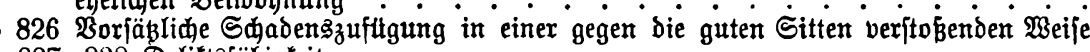

$\S 882 \pi, 828$ Delittęfähigłteit .

829 Befdräntte Gaftung der Deliftaunfahigen

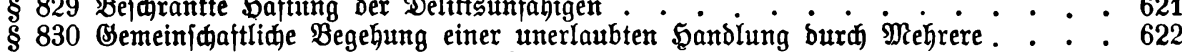

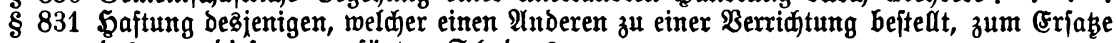
Des von biejem zugefügten Salabens

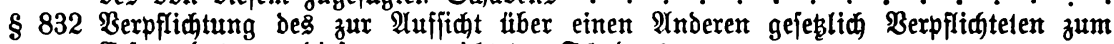
Erjałe bes von biejem angeriateten @đadenz............ 627

§§ 833, 834 Waftung für ben Durd Thiere angeridteten Sđjaden . . . . . . . . 628

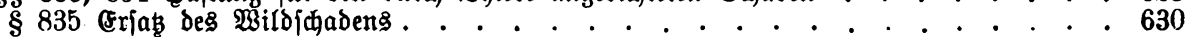

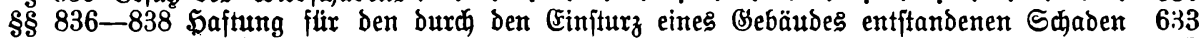

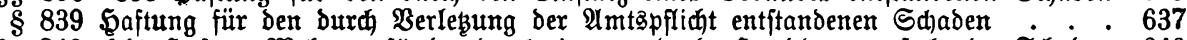

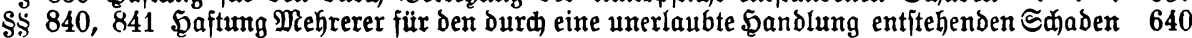

\$ 842 umfang Der $\mathfrak{D}$ aftung wegen ber gegen eine \$erjon veribbten unerlaubten \$andlung 641

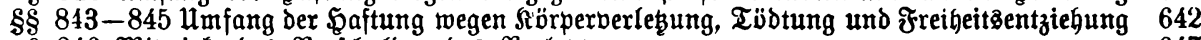

$\S 846$ Mitwirfendes Berjaulden bes Berlekten . . . . . . . . . . . . . . 647

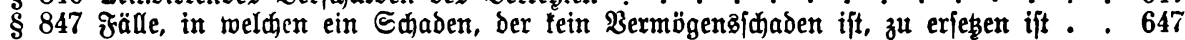

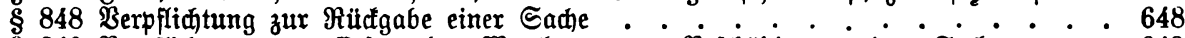

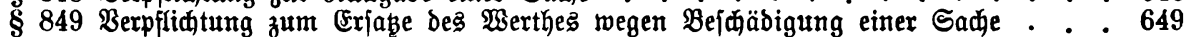

$\S 850$ Serwendungen des zur Serauşgabe der Sade Berpflidteten $. . . \quad . \quad . \quad .649$

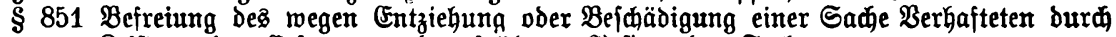

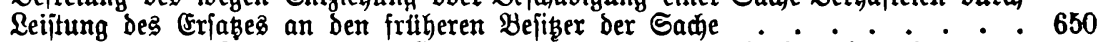

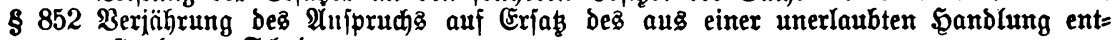

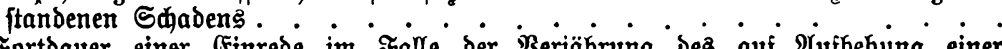

8853 fortbauter einer Finrede im Fralle der Berjährung des auf $\mathfrak{A}$ uffhebung einer Forderung geridteten $\mathfrak{A} \mathfrak{n}$ iprudis: 